\title{
Teachers' Implementation of Writing as a Process in English Classrooms: The Case of Ghimbi Preparatory School
}

\author{
Abeya Temesgen, Tamiru Olana* and Abeya Etana
}

Institute of Language Studies and Journalism, Wollega University, P.O. Box: 395, Nekemte, Ethiopia

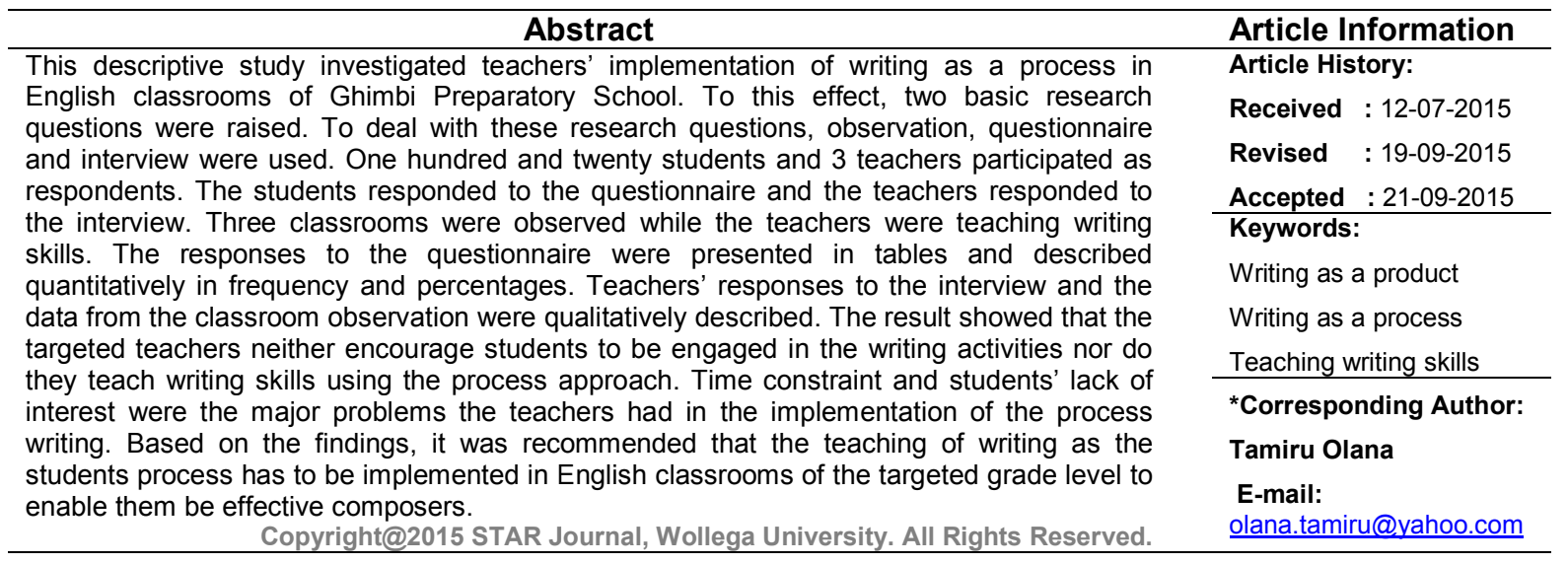

\section{INTRODUCTION}

The traditional view in language classes that writing functions primarily to support and reinforce patterns of oral language use, grammar and vocabulary--- "the product model", is being supplanted by a new model called the "process" model (Richards, 2004). In a similar manner, Kroll (1990), describes that the introduction of the process approach to ESL composition seems to have been motivated by dissatisfaction with controlled composition and the current-traditional approaches.

Writing is a series of forward and backward steps as writers think, reflect, revise, detour, start over, and repeat earlier steps. The job of teachers is to guide students through the process in order to help them become the best writers they can be. Teachers have crucial roles to help students use the stages of the writing as a process and to engage them in that creative process (White and Arndt, 1991).

The researchers overviewed that grade eleven English textbook contains writing sections with writing activities in each unit. Almost all the activities, except few, are suitable for teachers to teach writing in process. Each writing activity is guided by instructions on how to implement each step of the writing process. Therefore, investigating teachers' implementation of writing as a process in English classrooms has become important.

Currently, it is common to see many students who cannot construct correct and meaningful sentences let alone constructing acceptable paragraphs and essays. This might, among other variables, be resulted from ineffective implementation of teachers' writing as a process to teaching writing. In this area, Ho (2006) conducted a research on a topic "Effectiveness of using process approach to teach writing in six Hong Kong primary classrooms". His research findings showed that it is in general an effective approach to helping students improve their writing skills and attitudes towards writing at every level. With regard to local studies, Yonas (1996) conducted research on teaching writing as a process at first year level at AAU. His point of focus was to address first year students' perception of writing abilities before and after taking Freshman English at university level. He used observation and questionnaire, interview and pretest and post test as instruments of data collection.

From their informal observation, the researchers realized that English teachers in the targeted preparatory school do not seem to follow the stages of writing as a process in teaching the writing activities indicated in the students' textbook. Thus, since research work that addresses the issue of teachers' implementation of writing as a process seems scarce in the area, it has become important to investigate teachers' implementation of writing as a process in English classrooms.

\section{Approaches to Teaching Writing}

The discussion of the history of ESL composition focuses on the origins, principles, methods, and 
Abeya Temesgen et alo,

implications of the four most influential approaches of this period: controlled composition, current-traditional rhetoric, the process approach, and English for academic purpose (Kroll, 1990). When closely examined, the four approaches to teaching writing can be categorized under two major parts: the product approach and the process approach.

\section{The Product Approach}

In this approach, learning in general is understood as habit formation and language learning in particular is regarded as imitating the model in order to master the patterns of a language. The emphasis is on the memorization of facts rather than on problem solving and creative thinking (Yonas, 1996, p. 8). Studies show that in the product approach the roles of the students are to study structures and patterns of the language. Likewise, the teachers' roles include control over the students. The teacher is the sole authority and source of the writing abilities. As a result, the entire teaching-learning process is teacher-centered. Controlled or guided composition, current-traditional rhetoric, and English for Academic Purposes (EAP) are the sub-categories of the product approach.

\section{The Process Approach}

The process approach is based on the principle that learning is a process of discovery. As many research findings confirm, writing as a process is also process of discovering meaning. The process approach to writing has two major categories: the cognitive or classical approach and expressive or romantic approach (Yonas, 1996).

The Cognitive approach shows that writing is the means of problem solving which involves analysis and synthesis. Scholars like Flower and Hayes (1982) state that students are required to plan extensively concentrating on defining rhetorical problems, generating alternative solutions and arriving at supported conclusions. Students put their thoughts onto papers, reviewing, revising, editing and proofreading their work. The writers' mental process is central to the cognitive approach. The expressive approach believes that writing is considered as a creative act in which the process implies self- discovering other than problem solving. According to this approach, the writing lesson should be designed to promote students' power of writing proficiency. The writing tasks include diary or journal writing, writing personal essays in which students write freely (Yonas, 1996).

In more details, in the process approach, students are considered to be active participants, and the learning environment is flexible, collaborative, positive and nonthreatening type. Teachers' role is explicit: they are not only interested readers but facilitators, co-authors and coeditors in the composition process". Badger and White (2000), in Ho (2006, p. 2) reported that writing in a process approach is seen as predominantly to do with linguistic skills, such as planning and drafting, and there is much less emphasis on linguistic knowledge, such as knowledge about grammar and text structure. In this approach, students are taught planning, drafting, revising, editing, and publishing strategies at each stage of the writing process to help them write freely and arrive at a product of good quality.
Sci. Technol. Arts Res. J., July-Sep 2015, 4(3): 273-278

On the other side of this approach is the product model. Gabrielatos (2002), as cited in Hasan and Akhand (2010), describe that the product approach is a traditional approach in which students are encouraged to mimic a model text, usually is presented and analyzed at an early stage. In a typical product-oriented classroom, for example, students are supplied with a standard sample of text and they are expected to follow the standard to construct a new piece of writing. What differentiates a process focused approach from the product centered one is that the outcome of the writing as a process is not preconceived (White and Arndt, 1991).

The process approach treats all writing as a creative act which requires time and positive feedback to be done well. In process writing, the teacher moves away from being someone who sets students a writing topic and receives the finished product for correction without any intervention in the writing process itself. Good writers plan, revise, rearrange and delete text, reread and produce multiple drafts before they produce their finished document.

Pre-writing: As its name implies, pre-writing is any writing done before starting the actual writing. It is the time that one can use to experiment, to jot down a few quick ideas, to try out something new without having to try very hard, to take a little time to gather thoughts and choose a direction before starting to draft by free writing, questioning, making a list, clustering, preparing a scratch outline (Peha, 2002).

Writing the First Draft: It is the fastest part of the process, and the most frightening for it is a commitment. Murray (1972) mentions that this step may take as little as one percent of the writer's time. Here, students need to be prepared to put in additional thoughts and details that did not emerge during pre-writing. This time, there is no need to worry about spelling, grammar, punctuation and other errors that will require them time to correct the words and sentences (Langan, 2010). At this stage, teachers and are required to encourage students to work independently are expected to confer with students individually as they write. Praise and suggestions are also important.

Revising: This means that the students rewrite a paragraph or a paper building upon what has already been done in order to make it stronger. The purpose of the revising aspect of writing is to make sure that we have actually said what we intended to say (Raimes, 1983). It is like getting rid of all the junk and putting things in the right order. During this process, the contents should be unified, supported, and organized. The teacher should concentrate on its coherence, if anything is missing, or anything is extra. The individual sentence in the paragraph (writing) should use parallelism, consistent point of view, specific words, active verbs, using words effectively by avoiding slangs, cliché's, pretentious language. The teacher also can help correcting the leading errors of the students' writing. He can model reading his own writing (if any).

Editing and Proofreading: Editing is when students have already revised content but need to correct mistakes in terms of spelling, grammar, sentence structure, punctuation and word choice. At this stage, as the students check their papers for mistakes committed, they should focus on the form and on producing a finished 
Abeya Temesgen et alo,

piece of work. Editing is a line-by-line checking. It is the demanding, satisfying process of making each word right. Though students often find it hard, teachers can help with error correction and give organizational advice. More importantly, teachers should make sure that students have made thoughtful changes to their writing content before moving on to the final draft. Proofreading is the last step before publishing in the process of writing (Langan, 2010). The task of the teacher is to teach students to reread their own work more than once to check whether it really conveys what they want to convey to their readers. Moreover, the teacher is required to give comments and corrections on the content and form of the text.

Publishing: It is preparing a piece of writing so that it can be read, understood, and enjoyed by the public. The public, technically, is anybody, but practically, it is the people in the class, the teacher, and anybody else one decided to show his writing to. The main idea is that the publishing stage is the students' chance to prepare their writing in a way that will best reach their audience (Peha, 2002 , p. 9). After the students have incorporated the changes they have made in the editing and rewriting steps, they are expected to write or type their final draft. Then, they come to the final stage of the writing process, publishing. This is to say that they share the final product/ draft to the readers/ audience. The teacher is expected to encourage the students to publish their work in a variety of ways such as a class book, bulletin board, and letter to the editor, etc. Having an authentic audience beyond the classroom gives student writing more importance and helps students to see a direct connection between their lives and their literacy development.

The following model shows the stages of writing as a process from pre-writing to the publishing. Each stage has its own specific procedure to follow in the writing as a process as described previously.

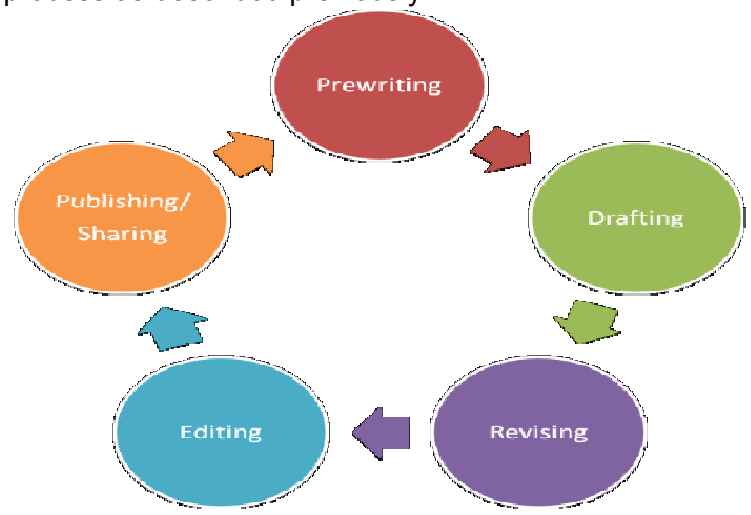

Figure 1: The writing as a process model

In addition to the roles they play in each stage of the writing process, teachers have some significant roles to play in the implementation of the writing process. They need to find out which components students are good at and which components they are poor at, and help them develop these. In other words, teachers should not be trying to remedy the written product so much as trying to facilitate the writing process.

Problems in Implementing the Process Writing

The writing process is more complex than considering the procedure of putting together a good piece of work. One of the disadvantages of getting students to
Sci. Technol. Arts Res. J., July-Sep 2015, 4(3): 273-278

concentrate on the process of writing is that it takes time (Harmer, 1988). All the stages in the process cannot be done within a few minutes or a period as the stages may involve a considerable amount of interaction between teacher and students and between the students themselves.

We believe that writing is needed to incubate, sift and shape ideas. We also know that time is one of the most precious resources of both teachers and students. So, writing is the one which most needs and benefits from time. That is why we advocate devoting classroom time to writing (White and Arndt, 1991). However, not all classroom time is spent actually on writing. Students may also react negatively to reworking the same material, but as long as the activities are varied and the objectives clear, then they will accept doing so. Another problem in writing is the inadequacy of the methods employed in teaching of composition. In the long term, the teacher and the students will start to recognize the value of writing as a process approach as their written work improves.

\section{MATERIALS AND METHODS}

The aim of this study was to investigate teachers' implementation of writing as a process at Ghimbi Preparatory School. Descriptive research design was used to fit the purpose of this study for that it is effective in describing actually existing phenomena and answering questions through descriptive analysis. Quantitative and qualitative research methods were used to analyze the data. The data from the questionnaire were analyzed quantitatively, and the data from observation and interview were described qualitatively.

\section{Rational for Site and Participants Selection}

Ghimbi Preparatory School was selected purposively because there is only one preparatory school in the town. The participants were 3 English teachers who were assigned to teach only grade 11 and 120 students, i.e., forty students each from the three teachers' sections. The three sections were also purposively selected while the selection of the students was made by using simple random sampling technique.

\section{Instruments}

To collect data for this study, observation, questionnaire and interview were used. Accordingly, three English teachers, along with the students in the three sections, were observed while the writing sessions were running. The observation helped the researchers collect necessary and actual data from the classroom interaction to make it as factual as possible. Similarly, a questionnaire, all with close-ended items, was set and administered to the 120 students. This tool was chosen because it enables to gather data from a large number of people in a short period of time. The questions were constructed in English, with simple terms, so that the students could easily understand. The items were adapted from the review literature. Thirdly, a semistructured interview with 5 items was designed to enable the researchers gather data from the teachers' opinions about the implementation of writing as a process in English classrooms. The interview was held with the three teachers in the Unit Leaders' Office. In the interview, the researchers used an interview guide which was adapted from Yonas' (1996) interview guide.

\section{Data Collection Procedures}


Abeya Temesgen et alo,

The researchers conducted the observations, administration of the questionnaire and the interview themselves. Accordingly, three teachers were observed while teaching writing. Then, the questionnaire was administered to the 120 students. The completed questionnaire was collected in one day time. Finally, the three targeted teachers were interviewed according to the interview guide set for this purpose.

\section{Methods of Data Analysis}

The researchers analyzed the data collected through the three data collection instruments by using quantitative and qualitative methods. The data from the questionnaire were analyzed quantitatively and tabulated and described in frequency and percentage. The observation and interview data were analyzed qualitatively and described using narrative description. Finally, the results were
Sci. Technol. Arts Res. J., July-Sep 2015, 4(3): 273-278

summarized; conclusions and recommendations were made based on the findings.

\section{RESULTS}

\section{Implementation of the Process Writing}

Writing activities are of great importance to students to practice writing as a process. One of the sources of these writing activities is the students' textbook. The researchers overviewed the textbook and proved that the activities are convenient for teachers to teach writing in a process. The students were requested to reply what procedures/ steps of writing as a process teachers use or follow while teaching the writing skills. The responses with the frequency and percentage are shown in Table 1 below,

Table 1: The steps teachers follow to teach writing as a process

\begin{tabular}{|c|c|c|c|c|c|c|}
\hline \multirow{3}{*}{ Procedures/steps } & \multicolumn{4}{|c|}{ Responses } & \multirow{2}{*}{\multicolumn{2}{|c|}{ Total }} \\
\hline & \multicolumn{2}{|c|}{ Yes } & \multicolumn{2}{|c|}{ No } & & \\
\hline & $\mathbf{F}$ & $\%$ & $\mathbf{F}$ & $\%$ & $\mathbf{F}$ & $\%$ \\
\hline Frequently engaging students in writing activities in the classroom & 83 & 69.2 & 37 & 30.8 & 120 & 100 \\
\hline Encouraging students to think and plan before starting writing any activity & 30 & 25 & 90 & 75 & 120 & 100 \\
\hline Guiding students to begin writing the first draft based on their plan & 27 & 22.5 & 93 & 77.5 & 120 & 100 \\
\hline Making students revise their writing (first draft) individually or in groups & 30 & 25 & 90 & 75 & 120 & 100 \\
\hline $\begin{array}{l}\text { Making students edit/proofread their writing and check for grammar, } \\
\text { mechanics, punctuation and spelling before the final draft }\end{array}$ & 24 & 20 & 96 & 80 & 120 & 100 \\
\hline $\begin{array}{l}\text { Encouraging students to publish or share their written work to the readers } \\
\text { (teachers and others) }\end{array}$ & 14 & 11.7 & 106 & 88.3 & 120 & 100 \\
\hline Making students comment and revise their own writing & 48 & 40 & 72 & 60 & 120 & 100 \\
\hline Encouraging students to follow the steps of the process writing & 52 & 43.3 & 68 & 56.7 & 120 & 100 \\
\hline
\end{tabular}

The responses of the students indicate 83 (69.2\%) of the participants replied that teachers frequently engage students in the writing activities in the classroom. Only 37 $(30.8 \%)$ participants reported that teachers do not engage students in the activities. This result is contrary to the result obtained from classroom observation and responses of the teachers to the interview question.

For example, one of the items in the observation checklist was whether or not teachers encourage students to be engaged in the writing activities. Teacher 1 and Teacher 2 didn't show this behavior. Only Teacher 3 managed to play the role. Item 1 of the interview questions requests whether or not teachers persistently encourage their students to be engaged in the writing activities. In response to this question, Teacher 1 and Teacher 2 reported that because the students are not interested in writing activities, they do not encourage them to be engaged in the writing activities. Teacher 3 , though he tried to encourage, as he reported, also shared the opinion of the two teachers. The reason why he didn't encourage them was that the background knowledge of the students was poor. Therefore, the evidence of the researcher during the actual classroom observation along with the opinions of the teachers overweighs the students' responses.

As to the principle of process writing, students have to be fully engaged in the writing activities. The activities in the prewriting stage need to be practiced by students in the classroom. This must be encouraged by the teacher. The teachers need to be available near the students when they are doing the thinking, planning and organizing ideas. That is to say teachers have the role of advising, guiding, encouraging and facilitating the process. Encouraging students to be engaged in the activities of writing enables them to feel responsible for their own writing at any stage. The researchers observed that teachers were not encouraging students for the topics they were teaching.

Majority of the participants, that is $68(56.7 \%)$ out of 120 , replied that teachers do not encourage students to follow the steps of the process writing. Fifty two (43.3\%) reported that teachers encourage students to follow the steps of writing as a process when writing the activities. One of the items in the observation checklist was whether or not the teachers make students practise writing following the steps of process writing. The results of the classroom observation supported the students' responses which say the teachers do not make the students follow the steps of the writing process. In the same manner when replying to the question in the interview, the three teachers (T1, T2 and T3) reported that they rarely make students follow the steps of writing as a process when they teach the writing skills.

As far as the specific steps of writing as a process are concerned, one of the roles of teachers in implementing the writing as a process is to encourage students to think and plan before starting to write any activity. The participants were requested whether the teachers do this or not. Thirty $(25 \%)$ of the participants replied that the teachers make students think and plan before starting to write. Whereas, $90(75 \%)$ out of 120 participants reported that the teachers do not encourage students to begin with thinking and planning before starting to write.

As stated above, the classroom observation witnessed that the three teachers didn't make students start by prewriting. They simply explained the activity and instructed the students to begin writing without giving 
Abeya Temesgen et alo,

them any motivating activities. The teachers responded to the interview questions saying that they do not follow the steps of writing as a process because there is no time to follow all the steps as the textbook is vast. These results reveal that the targeted teachers do not encourage students to follow the steps of writing as a process.

With regard to the fourth item in Table 1 above, the students were asked to make sure whether or not teachers guide them to begin writing the first draft. Twenty seven $(22.5 \%)$ out of 120 responded that the teachers applied this procedure, whereas, $93(77.5 \%)$ of the respondents replied that teachers do not guide them to begin the next step. The classroom observation data also depicted that the teachers were not following the steps. They simply instruct the students to write the activities. The teachers' responses to the interview questions also supported the students' responses and the result of the classroom observation. Thus, it is easy to imply that the targeted teachers do not teach the writing activities using a step -by-step process.

Students were requested to make sure whether teachers make them revise their writing either individually or in groups. As can be seen from Table 1 above, only 30 $(25 \%)$ of the respondents reported that the targeted teachers make them revise their writing. Ninety $(75 \%)$ out of 120 students replied that teachers do not make them revise their first draft (writing). The classroom observation also supports the students' responses. During the classroom observation, the teachers didn't really give time for revision which is the key stage in the writing development.

Editing and proofreading together are the stages where students check for grammatical constructions, punctuations, spelling and mechanics. The students were
Sci. Technol. Arts Res. J., July-Sep 2015, 4(3): 273-278

asked to tell whether the teachers make them edit/ proofread their writing after the revision stage. Twenty four $(20 \%)$ out of the total participants reported that the targeted teachers make the students do the editing, but $96(80 \%)$ of them replied that the teachers do not help students edit/proofread their writing. The classroom observation and the teachers' opinions about the extent to which they implement the steps of the process supported the students' responses.

Publishing/sharing their product to the audience is the last stage of the process. Students were requested to make sure whether their teachers encourage them to share their written work to the readers (teachers, students, audience). In this regard, only $14(11.7 \%)$ replied that teachers encourage students to share/publish whereas, $106(88.3 \%)$ of the respondents reported that the targeted teachers do not do that. The results of the classroom observation and the responses of the teachers to the interview questions also showed that the targeted teachers do not make students publish/share their work.

Summary, majority of the students replied that teachers do not make use of the steps of process writing. The classroom observation and interview data also convincingly proved that the targeted teachers were not following the steps of the process writing.

The Actual Problems in Implementing Process Writing

The students were requested to state what problems they observed in teachers' implementation of the steps of the writing process when teaching writing skills. They were required to agree or disagree to the statements in Table 2, which contains the assumed problems and the responses of the students to the extent of their agreement or disagreement described in frequency and percentage.

Table 2: Actual problems in implementing process writing

\begin{tabular}{|c|c|c|c|c|c|c|c|c|c|c|}
\hline \multirow{3}{*}{ Items } & \multicolumn{8}{|c|}{ Extent of agreement/disagreement } & \multirow{2}{*}{\multicolumn{2}{|c|}{ Total }} \\
\hline & \multicolumn{2}{|c|}{ SA } & \multicolumn{2}{|c|}{ A } & \multicolumn{2}{|c|}{ D } & \multicolumn{2}{|c|}{ SD } & & \\
\hline & $\mathbf{F}$ & $\%$ & $\mathbf{F}$ & $\%$ & $\mathbf{F}$ & $\%$ & $\mathbf{F}$ & $\%$ & $\mathbf{F}$ & $\%$ \\
\hline The process takes more time & 30 & 25 & 70 & 58.3 & 18 & 15 & 2 & 1.7 & 120 & 100 \\
\hline Students' lack interest on writing skills & 37 & 30.8 & 46 & 38.3 & 23 & 19.2 & 14 & 11.7 & 120 & 100 \\
\hline The writing tasks are beyond ability of the students & 30 & 25 & 21 & 17.5 & 23 & 19.2 & 46 & 38.3 & 120 & 100 \\
\hline
\end{tabular}

As can be observed from Table 2 above, out of 120 respondents, $30(25 \%)$ strongly agreed that writing as a process takes more time. The majority of the respondents that is $70(58.3 \%)$ agreed that teaching writing as a process takes/consumes more time. The rest, $18(15 \%)$ of the participants, reported they disagree that the teaching of writing as a process takes more time. Only $2(1.7 \%)$ of the respondents strongly disagreed that teachers fail to implement the process not due to the fact that it takes/consumes time. Teachers' (T1, T2 and T3) responses to the interview question also supported that time is one of the actual problems that has an impact on the implementation of the writing as a process at that level.

In Table 2, Item 2 above, 37 (30.8\%) and 46 (38.3\%) the respondents respectively strongly agreed and agreed that students are not interested in writing and thereby not performing the writing process. This was also confirmed by (T1, T2 and T3) during the interview session. The rest $23(19.2 \%)$ and $14(11.7 \%)$ of the respondents respectively disagreed and strongly disagreed that students' lack of interest to writing cannot be a possible problem to the teachers to implement the writing process. It can be seen that students' lack of interest is one of the actual problems to be noted. Actually, though the students were not interested in practicing the writing skills, it is the teachers' role to encourage or initiate the students to be engaged in any writing activities.

Students were also requested to suggest whether or not the writing tasks are above the ability of the students. In Item 3, $30(25 \%)$ of the respondents strongly agreed that the writing tasks are beyond the ability of the students. Additionally, $21(17.5 \%)$ of the respondents agreed that the case is of course a possible problem. On the other side, $23(19.2 \%)$ disagreed that the problem could be considered potential. The rest, 46 (38.3\%), strongly disagreed that the tasks are beyond the ability of the students. Thus, one can deduce that the writing tasks in the students' textbook are not considered to be much difficult. This finding was also supported by the data from 
Abeya Temesgen et al.,

the classroom observations and the teachers' responses to the interview questions.

\section{DISCUSSION}

The study was conducted by using three data collection instruments: classroom observation, questionnaire and interview. They studied teachers' actual implementation of writing as a process in English classrooms by using classroom observations.

The results of the study revealed that the targeted teachers were not seen guiding students to begin writing based on the first step of the process writing. Scholars like Langan (2010), as indicated in the review literature, state that teachers are required to encourage students to work independently but they are also expected to confer with students as they write. But what is being practiced in the targeted school is different; teachers fail to implement what is expected from them.

It is clear that revision of writing enables students to make sure that they have actually said what they intended to say (Raimes, 1983). Though it is the role of teachers to show students how to revise the contents of their writing, the targeted teachers do not make students revise their writing. The data also proved that the teachers do not make students edit/proofread their written work. However, as Langan (2010) stresses, the revision stage is where teachers should make sure that students have made thoughtful changes to their writing contents before moving on to the final draft. Thus, the targeted teachers should make students reread their writing to check whether it really conveys what they want to convey through this stage.

Writing in general and writing as a process in particular is a complex issue as it goes beyond simply putting ungrammatical and illogical organization of sentences merely once. That means it takes time to go through all steps (Harmer, 1988). The researchers also believe that all the stages in the process cannot be done within a few minutes or a period as the stages may involve a considerable amount of interaction between teacher and students and between students themselves. We also know that time is one of the most precious resources of both teachers and students. In the targeted school, however, teachers do not effectively use the writing time. Thus, we want to emphasise that as the use of writing as a process is supported by research, teachers should devote classroom time to writing as they do for other skills (White and Arndt, 1991).

The researchers do not believe that writing can be taught only by using a process approach; we know that not all students see this approach as good thing. There are times when process writing is simply not appropriate, either because classroom time is limited or because when we want students to write quickly as part of the communication game. However, this should not prevent the targeted teachers from dealing the process writing with their students and encourage them to practice.

\section{CONCLUSIONS}

On the bases of the above findings, it can be concluded that the steps of writing as a process were not implemented in the English classrooms of the grade level. Thus, it requires due attention as writing as a process
Sci. Technol. Arts Res. J., July-Sep 2015, 4(3): 273-278

enables students to think critically and to write creatively. Regarding the actual problems in implementing the writing process, shortage of time and students' lack of interest were the most identified problems to be mentioned and require solutions. Based on the findings of this study, recommendations were made:

1. Writing is taught in a process. Therefore, it is recommended that English teachers need to be informed about the teaching of writing as a process and its implementation. In-staff training could help to familiarize teachers with writing as a process and equip them to implement as it should be.

2. Teachers need to play the role of guiding, advising, encouraging and facilitating.

3. Writing is a time-taking job. It cannot be performed automatically. Therefore, teachers may decide on which steps to perform within the first period and which ones for the next so as to use the allotted time properly.

4. The researchers believe that there might remain some issues that have not been critically and sufficiently dealt with. Therefore, it will be advisable to conduct further research on:

i. The relationship between the nature of the writing tasks/activities of the targeted grade level and the background knowledge of the students at high school.

ii. The actual problems mentioned in the discussions and conclusions need to be investigated further and get remedial solutions.

\section{Conflict of Interest}

Conflict of interest none declared.

\section{REFERENCES}

Harmer, J. (1988). The practice of English language teaching. Pearson: Longman.

Hasan, M. and Akhand, M. (2010). Approaches to Writing in EFL/ESL Context: Balancing Product and Process in Writing Class at tertiary Level. Journal of NELTA 15 (12): 78 .

Ho, B. (2006). Effectiveness of using the process approach to teach writing in six Hong Kong primary classrooms. City University of Hong Kong.

Kroll, B. (1990). Second Language writing: Research insight for the classroom. California State University, Northridge. Cambridge University Press.

Langan, J. (2010). Exploring writing; sentences and paragraphs, $2^{\text {nd }}$ edition: Atlantic Cape Community College.

Murray, D. (1972). Teach writing as a process not product. The Leaflet 1-14.

Peha, S. (2002).The writing process notebook. Available at http://www.ttms.org/PDFs/04\%20Writing\%20Process $\% 20$ v001\%20\%28Full\%29.pdf

Raimes, A. (1983). Techniques in teaching writing. Oxford University Press.

Richards, J. C. (2004). Second language writing. Cambridge University Press. Pp.1.

White, R. and Arndt, V. (1991). Process writing: Longman handbook for language teachers. London. Pp. 5.

Yonas Adaye (1996). Teaching writing as a process at the first year level at A.A.U. with special reference to College English: MA Thesis. 